\title{
The Influence of Water Activity on Double Layer Parameters on the Interface Mercury/Chlorates (VII) in the Presence of Cysteine
}

\author{
Agnieszka Nosal-Wiercińska \\ M. Curie-Skłodowska University, Faculty of Chemistry, Department of Analytical Chemistry and Instrumental Analysis, \\ M. Curie-Skłodowska Sq. 3, 20-031 Lublin, Poland (E-mail: anosal@poczta.umcs.lublin.pl)
}

RECEIVED NOVEMBER 22, 2011; REVISED JULY 23, 2012; ACCEPTED DECEMBER 11, 2012

\begin{abstract}
The influence both the cysteine concentration and water activity on the double layer parameters on the interface mercury/ chlorates (VII) was examined. The adsorption parameters for the double layer were calculated from a double-layer differential capacity measurement extrapolated to zero frequency.

The values of the relative surface excess increase of the cysteine concentration and chlorates (VII) solutions. It was found that the values of free adsorption energy and interactions constants, obtained from Frumkin and virial isotherms, depend on the supporting electrolyte concentration. The changes of determined parameters in the function of water activity water point at the participation of $\mathrm{ClO}_{4}^{-}$ions in the adsorption processes, or that in the double layer the electrostatic interactions between the dipoles of $\mathrm{H}_{2} \mathrm{O}$ and cysteine compounds exist.(doi: 10.5562/cca2022)
\end{abstract}

Keywords: cysteine, adsorption, water activity, differential capacity, mercury electrode

\section{INTRODUCTION}

Cysteine ((2R)-2-amino-3-mercaptopropionic acid) is an endogenous aminoacid, which is formed in the reaction of a sulphur atom transfer from methionine to serine with the participation of ATP (adenosine triphosphate) molecule. Cysteine (RSH) plays the key role in the formation of protein tertiary structures. After decarboxylation the cysteine as a cysteamine is present in coenzyme A and its thiol group as an active centre of this coenzyme participates in many reactions, for example in transfer of dicarbonic acyl groups, in biosynthesis of fatty acids as well as many esters and aminoacids and in metabolic processes.

Cysteine is a biologically important substance in such fields as food chemistry and clinical chemistry. Cysteine feeds, regenerates and strengthens hair, restoring them a sheen and a healthy look. Moreover, cysteine liquidates inflammatory states of skin, moistens and protects skin against UV radiation. ${ }^{1}$ Cysteine is applied as well as corrosion inhibitor, for instance of copper. ${ }^{2}$

The electrochemical behaviour of cysteine at mercury electrode was the subject of many papers ${ }^{3-11}$ for the sake of strong specific interactions between sulphur and mercury.

It seems that the mechanism proposed by Stankovich and Bard $^{12}$ as well as Heyrovsky and co-workers ${ }^{13,14}$ explains best of all the cysteine-mercury interaction.
The reaction of cysteine with mercury ions is the basis of its electrolytic activity on mercury electrodes. The reaction consists of electro-oxidation of mercury in two separate steps, to cysteine mercurous thiolate $\mathrm{Hg}_{2}(\mathrm{SR})_{2}$ and cysteine mercuric thiolate $\mathrm{Hg}(\mathrm{SR})_{2}$, respectively, which are both strongly adsorbed at the electrode. $^{14}$

$$
\begin{aligned}
& 2 \mathrm{Hg} \rightleftarrows \mathrm{Hg}_{2}^{+2}+2 \mathrm{e}^{-} \\
& \mathrm{Hg}_{2}^{+2}+2 \mathrm{RSH} \rightleftarrows \mathrm{Hg}_{2}(\mathrm{SR})_{2}+2 \mathrm{H}^{+}
\end{aligned}
$$

cysteine mercurous thiolate

$$
\mathrm{Hg}_{2}(\mathrm{SR})_{2}+2 \mathrm{RSH} \rightleftarrows 2 \mathrm{Hg}(\mathrm{SR})_{2}+2 \mathrm{e}^{-}+2 \mathrm{H}^{+}
$$

cysteine mercuric thiolate

The path of the electrode reaction is determined by the form of mercury thiolates in the adsorbed state, which depends strongly on the $\mathrm{pH}$ of the solution. ${ }^{14,15}$

Lovric and co-workers ${ }^{16,17}$ and Piech ${ }^{18}$ consider the processes of cysteine mercury thiolates forming as a formation of the deposit of sparingly soluble salt on the electrode surface, the same as the sedimentation of $\mathrm{Hg}_{2} \mathrm{Cl}_{2}$ or $\mathrm{HgS}$. Whereas the other authors consider this process as the electrosorption reaction in which the ligand $R S-$ is adsorbed at the electrode surface by 
forming a more or less polarized covalent bond with mercury atoms. ${ }^{19,20}$

The paper presented herein is the part of a broader project concerning the influence of water activity on the structure of the mercury/amino acid- $\mathrm{H}_{2} \mathrm{O}-\mathrm{ClO}_{4}^{-}$interface. Previous studies of methionine adsorption on mercury electrode in $0.5-8 \mathrm{~mol} \mathrm{dm}^{-3}$ chlorate (VII) indicate the strongest adsorption of methionine in $8 \mathrm{~mol} \mathrm{dm}^{-3}$ chlorate (VII). ${ }^{21,22}$

In the present paper the influence of cysteine and water activity on the double layer parameters on the interface mercury/ chlorates (VII) was examined.

The choice of water as the medium, which similarly as cysteine influences the double layer parameters on the interface mercury/ chlorates (VII) was determined by the specific water properties and the fact, that most of the chemical processes proceed in water environment.

The results of studies will allow to explain more precisely the effect of cysteine on the mechanism and kinetics of $\mathrm{Bi}(\mathrm{III})$ ion electroreduction.

\section{EXPERIMENTAL}

The measurements were carried out in thermostated cells at $298 \mathrm{~K}$ with electrochemical analyzer Autolab/ GPES (Version 4.9) (Eco Chemie, Ultrecht Netherlands). The investigations were conducted in a threeelectrode cell with a hanging controlled growth mercury drop electrode (CGMDE) (Entech, Cracow, Poland) as the working electrode (electrode area was 0.009487 $\mathrm{cm}^{2}$, drop time was $3 \mathrm{~s}$ ), $\mathrm{Ag} / \mathrm{AgCl} /$ saturated $\mathrm{NaCl}$ as the reference electrode and a platinum spiral as the counter electrode. The reference electrode was connected to the electrolytic cell via an intermediate vessel filled with the solution to be investigated.

Analytical-grade reagents: L-cysteine (Fluka), $\mathrm{NaClO}_{4}$ (Fluka) and $\mathrm{HClO}_{4}$ (Fluka) were used without further purification. The solutions were prepared from freshly double - distilled water. Before measurements the solutions were deaerated using high-purity nitrogen. Nitrogen was passed over the solution during the measurements.

The supporting electrolytes were $x \mathrm{~mol} \mathrm{dm}^{-3} \mathrm{Na}$ $\mathrm{ClO}_{4}+1 \mathrm{~mol} \mathrm{dm}^{-3} \mathrm{HClO}_{4}$ (where $0 \leq x \leq 7$ ).

The cysteine solutions were prepared directly before the measurements. The range of concentrations studied of cysteine were $0.5-80 \cdot 10^{-3} \mathrm{~mol} \mathrm{dm}^{-3}$.

\section{Elaboration of Experimental Data}

The double layer capacity $\left(C_{d}\right)$ was measured using the AC impedance technique with the electrochemical analyzer Autolab (as above). The reproducibility of the average capacity measurements was $\pm 0.5 \%$.
For the whole polarization range, the capacity dispersion was tested at different frequencies between 200 and $1000 \mathrm{~Hz}$. To obtain the equilibrium values of differential capacity, the linear dependence of capacity on square element from frequency was extrapolated to zero frequency. This procedure assumes that the impedance of the double-layer is equivalent to a series capacityresistance combination and the rate of adsorption is diffusion-controlled. $^{23}$

The potential of zero charge $\left(E_{z}\right)$ was measured for each solution by the method of streaming mercury electrode, ${ }^{24,25}$ with an accuracy of $\pm 0.1 \mathrm{mV}$.

The surface tension at potential of zero charge $\left(\gamma_{z}\right)$ was determined using the method of highest pressure inside the mercury drop presented by Schiffrin. ${ }^{26}$ The surface tension values were determined with an accuracy of $\pm 0.2 \mathrm{~m} \mathrm{Nm}^{-1}$.

The adsorption parameters were derived by the integration of capacity-potential dependencies from the $E_{z}$ values. No corrections for the effects of the medium on the activity of the supporting electrolyte ${ }^{27,28}$ and the activity coefficient of the adsorbate were made. ${ }^{29}$

The values of charge density $\sigma_{M}$ on the electrode surface and the values of surface tension $\gamma$ obtained from the integration of the differential capacity curves were used for the calculation of Parsons auxiliary function $\xi,{ }^{30} \xi=\gamma+\sigma_{M} E$ and the surface pressure $\Phi$.

$\Phi=\Delta \xi=\xi^{0}-\xi$, where $\xi^{0}$ refers to the supporting electrolyte containing cysteine.

In accordance to Gibbs adsorbance isotherm the relative surface excesses $\left(\Gamma^{\prime}\right)$ of adsorbate were determined at constant charge $\sigma_{M}$ with the support of equation:

$$
\Gamma_{\text {adsorbate }}^{\prime}=\left(\frac{1}{R T}\right)\left(\frac{\mathrm{d} \Phi}{\mathrm{d} \ln c}\right)_{\sigma_{M}}
$$

where $c$ is the bulk concentration of adsorbate.

For the studies of cysteine adsorption the Frumkin isotherm was used:

$$
\beta x=[\Theta /(1-\Theta)] \exp (-2 A \Theta)
$$

where $x$ is the molar fraction of cysteine in the solution, $\quad \beta$ is the adsorption coefficient $\beta=\exp \left(-\Delta G^{0} / R T\right), \Delta G^{0}$ is the standard Gibbs energy of adsorption, $A$ is the interaction parameter and $\Theta$ is the coverage $\Theta=\Gamma^{\prime} / \Gamma_{S}$. The surface excess at saturation $\left(\Gamma_{S}\right)$ was estimated by extrapolating of the $1 / \Gamma^{\prime}$ vs $1 / c_{\text {adsorbate }}$ at different charges to $1 / c_{\text {adsorbate }}=0$. The values of parameter $A$ were calculated from the slopes of the lines of the linear test of the Frumkin isotherm. The corresponding values of $\Delta G^{0}$ were determined by extrapolation of the line $\ln [(1-\Theta) x / \Theta]$ versus $\Theta$ to the value $\Theta=0$. 
The virial isotherm was also used to describe the adsorption of cysteine:

$$
\ln \beta c=\Gamma^{\prime}+2 B \Gamma^{\prime}
$$

$c$ is the molar concentration of cysteine, $B$ is the second virial coefficient.

The values of the second virial coefficient $B$ were calculated from the slopes of lines of the linear test of the virial isotherm and the corresponding $\Delta G^{0}$ values were obtained from the intercepts of these lines with the axis $\log \left(\Gamma^{\prime} / c\right)$ using the standard state of $1 \mathrm{~mol} \cdot \mathrm{dm}^{-3}$ in bulk solution and one molecule on the surface.

\section{RESULTS AND DISCUSSION}

The course of differential capacity curves on mercury in $5 \mathrm{~mol} \mathrm{dm}^{-3}$ chlorates (VII) solutions containing 0.5 $80 \cdot 10^{-3} \mathrm{~mol} \mathrm{dm}^{-3}$ cysteine points at the change of differential capacity of double layer on the interface mercury/ chlorate (VII) connected with the presence of cysteine in solution (Figure 1a, 1b).

With the increase of cysteine concentration the hump on the curves $C_{d}=f(E)$ is decreasing and shifted towards the negative potentials (Figure 1a). Such behaviour reflects the removal of water molecules from electrode surface as a result of cysteine adsorption.

The same effect is observed with the increase of chlorate (VII) concentration in the presence of all the cysteine concentrations examined. In the range of more positive potentials on the curves $C_{d}=f(E)$ the peaks appear and their heights increase with the increase of the concentration of examined aminoacid (Figure 1b). The peak potential does not depend on cysteine concentration in solution.

Cysteine molecule interacts strongly with mercury with the help of sulphur atom included in its structure.

Heyrovsky finds that the products of anodic mercury oxidation by cysteine: mercurous thiolate $\mathrm{Hg}_{2}(\mathrm{SR})_{2}$ and cysteine mercuric thiolate $\mathrm{Hg}(\mathrm{SR})_{2}$ ad-sorbed strongly at the electrode. ${ }^{13,14}$ From electrocapillary measurements ${ }^{14}$ results that for cysteine concentrations higher than $0.5 \cdot 10^{-3} \mathrm{~mol} \mathrm{dm}^{-3}$ more protons are released in the electrode reaction, the products become more protonated and at the negative side of the adsorption region (about $200 \mathrm{mV}$ ) the formation of the orien-ted surface layer of mercurous thiolate $\mathrm{Hg}_{2}(\mathrm{SR})_{2}$ proceeds. Going towards the more positive potentials, where the reaction $\mathrm{Hg}_{2}(\mathrm{SR})_{2}+2 \mathrm{RSH} \rightleftarrows 2 \mathrm{Hg}(\mathrm{SR})_{2}+2 \mathrm{e}^{-}+2 \mathrm{H}^{+} \quad$ takes place, the long molecule of mercuric thiolate with a linear central $\mathrm{S}-\mathrm{Hg}-\mathrm{S}$ part, when fully protonated, has both ends electrostatically repelled from the neighbouring molecu-les: that leads to a profound change of the adsorbed film. ${ }^{14}$

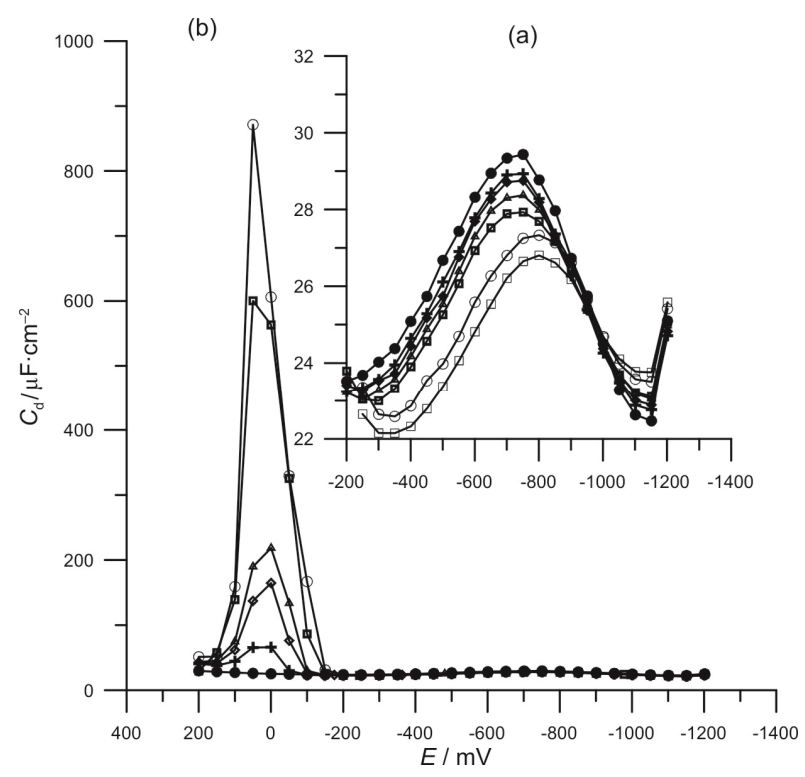

Figure 1(a,b). Differential capacity-potential curves of the mercury electrode in $5 \mathrm{~mol} \mathrm{dm}{ }^{-3}$ chlorate (VII) with various concentrations of cysteine (in $\mathrm{mol} \cdot \mathrm{dm}^{-3}$ ): (•) 0 , (+) $5 \cdot 10^{-4}$,

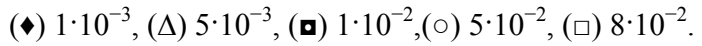

For the identical cysteine concentrations with the increase of chlorate (VII) concentration from $1 \mathrm{~mol}$ $\mathrm{dm}^{-3}$ to $8 \mathrm{~mol} \mathrm{dm}^{-3}$ (water activity is changing from 0.962 to 0.543$)^{31}$, the hump at $C_{d}=f(E)$ curves decreases and shifts towards the negative potentials (Figure $2 \mathrm{a}$ ). There are two reasons for the appearance of the hump in the capacity curve: reorientation of water and

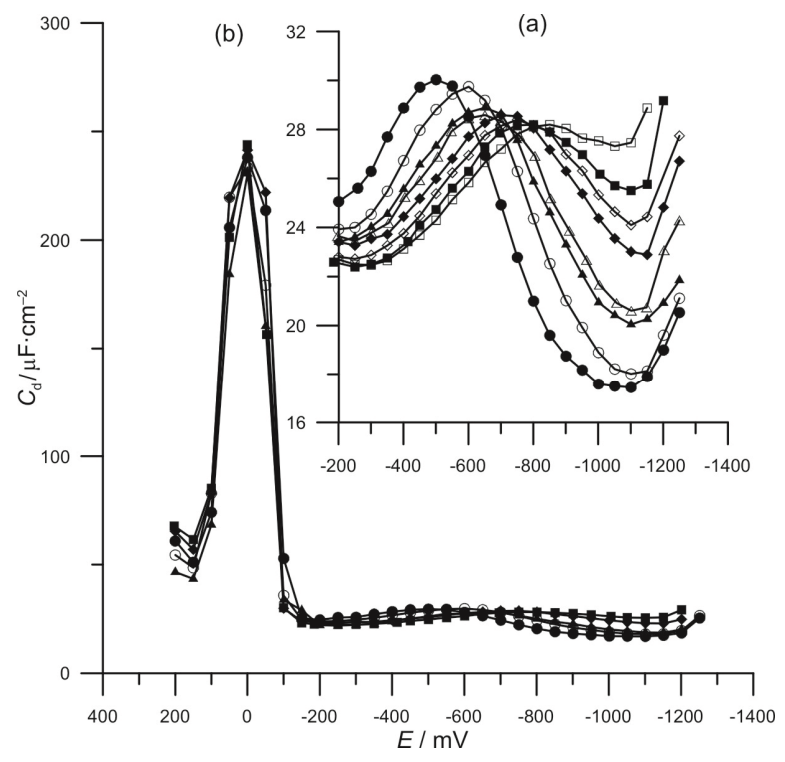

Figure 2(a,b). Differential capacity-potential curves of the mercury electrode in $1-8 \mathrm{~mol} \mathrm{dm}^{-3}$ chlorates (VII) with $1 \cdot 10^{-3}$ $\mathrm{mol} \cdot \mathrm{dm}^{-3}$ cysteine. Concentrations of chlorates (VII) (in

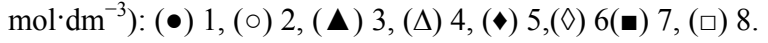




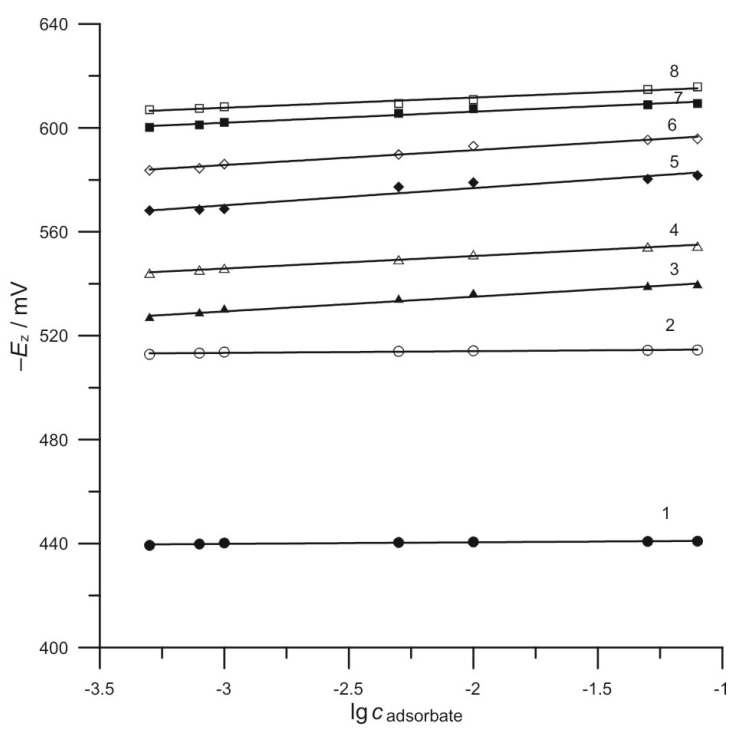

Figure 3. Dependence of the potential of zero charge $E_{\mathrm{z}} v s \mathrm{lg}$ $c_{\text {adsorbate }}$ for cysteine-chlorates (VII) systems. Concentrations of chlorate (VII) (in $\mathrm{mol} \mathrm{dm}^{-3}$ ) indicated by each line.

changes in the electrostatic interactions between adsorbed molecules cysteine. ${ }^{32,33}$ Both the peaks height and the peaks potential (about $0 \mathrm{~V}$ ) occuring on the differential capacity curves $C_{d}=f(E)$ do not change (Figure 2b).

For all the examined supporting electrolyte concentrations it was concluded that with the increase of cysteine concentration the zero charge potential $E_{z}$ values shift slightly towards negative potentials (Figure

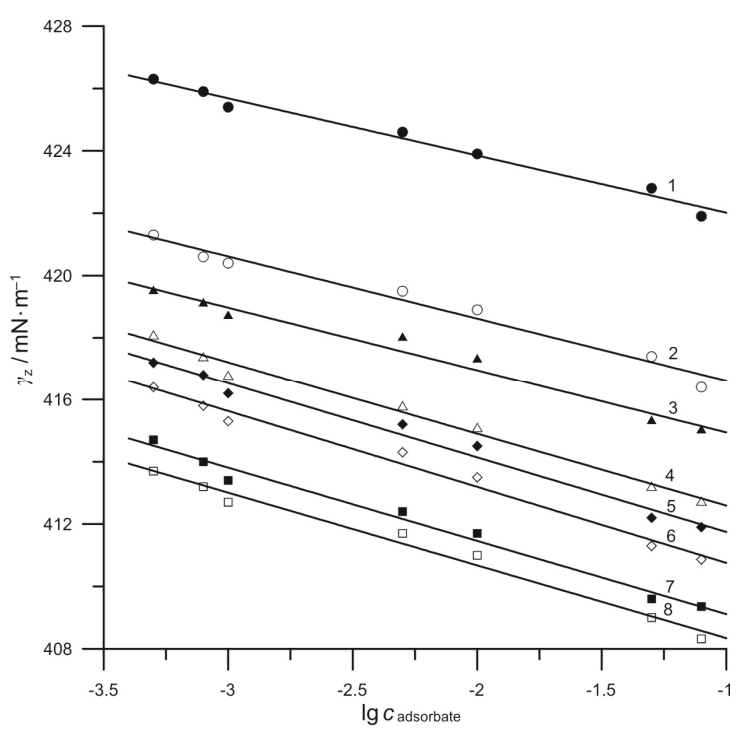

Figure 4. Dependence of surface tension values at potential of zero charge $\gamma_{z}$ vs $\lg c_{\text {adsorbate }}$ for cysteine-chlorates (VII) systems. Concentrations of chlorate (VII) (in $\mathrm{mol} \cdot \mathrm{dm}^{-3}$ ) indicated by each line.

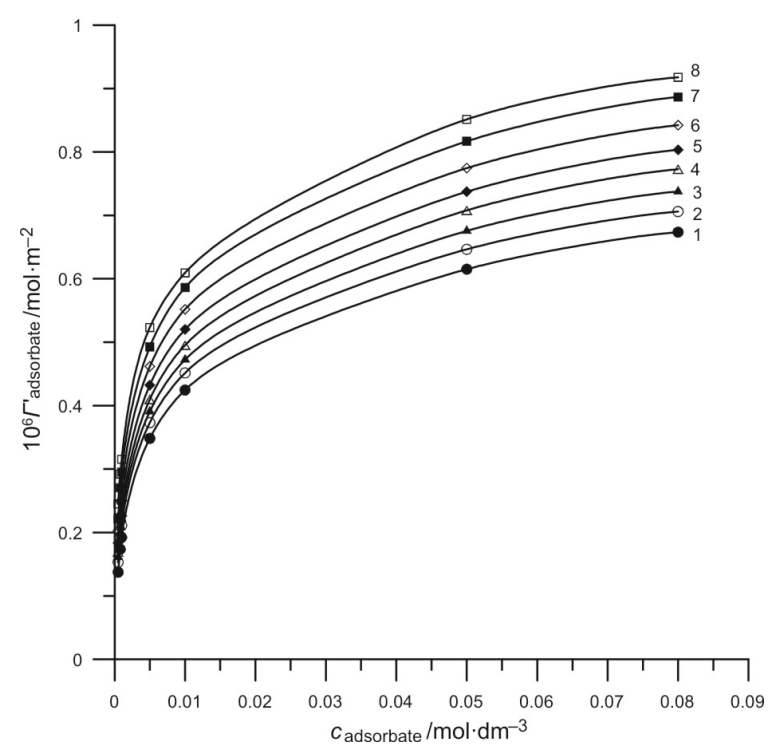

Figure 5. Relative surface excess $\Gamma^{\prime}$ of adsorbate as a function of adsorbate concentration in the bulk for various concen-

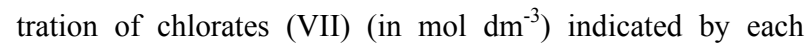
curve. The electrode charge $\sigma_{M}=0 \mu \mathrm{C} \mathrm{cm}^{-2}$.

3) and the surface tension values at potential of zero charge $\gamma_{z}$ decrease (Figure 4).

The linear dependences $E_{z}=f\left(c_{\text {adsorbate }}\right)$ (Figure 3) obtained for all the chlorates (VII) concentrations examined point at specific adsorption of adsorbate on mercury electrode. ${ }^{34}$

Figure 5 presents the dependences $\Gamma^{\prime}=f\left(c_{\text {adsorbate }}\right)$ in 1-8 $\mathrm{mol} \mathrm{dm}^{-3}$ chlorates (VII) for $\sigma_{M}=0$.

The values of relative surface excesses $\Gamma^{\prime}$ increase with the increase of cysteine concentration for all studied electrode charges. The increase of chlorates (VII) concentration 1 to $8 \mathrm{~mol} \mathrm{dm}^{-3}$ causes as well the increase of values of relative surface excesses $\Gamma^{\prime}$. It should be emphasized that the results concerning the adsorption of molecules from very concentrated solutions of chlorates (VII) can be saddled with big mistakes, because in thermodynamic calculations the activity coefficients were not taken into account.

\section{Adsorption Isotherms}

In the description of adsorption the following isotherms were used: Frumkin and virial.

Table 1 shows the values of surface occupied by one molecule of the adsorbate $S$.

The decrease of $S$ values with the increase of chlorates (VII) concentration points at water influence, present on the electrode surface, on the obtained results of calculations.

Figure 6 presents the linear test of the Frumkin isotherm for chosen electrode charge. 
Table 1. Values of the surface occupied by adsorbate molecule at a mercury/chlorate (VII) interface (S) for the examined concentrations of chlorates (VII) and water activity. Water activity $\left(a_{\mathrm{H}_{2} \mathrm{O}}\right)$ is taken from Ref. 31

\begin{tabular}{ccccccccc}
\hline$c_{\text {chlorates }(\mathrm{VII})} / \mathrm{mol} \mathrm{dm}^{-3}$ & 1 & 2 & 3 & 4 & 5 & 6 & 7 & 8 \\
$a_{\mathrm{H}_{2} \mathrm{O}}$ & 0.962 & 0.927 & 0.885 & 0.832 & 0.774 & 0.704 & 0.628 & 0.543 \\
$S / \mathrm{nm}^{2}$ & 14.7 & 14.3 & 13.5 & 13.0 & 10.8 & 6.90 & 5.20 & 3.60 \\
\hline
\end{tabular}

Table 2. The values of adsorption energy $\left(\Delta G^{\circ}\right)$ obtained from Frumkin isotherm and virial isotherm for the chosen charges for $1-8 \mathrm{~mol} \cdot \mathrm{dm}^{-3}$ chlorates (VII) systems containing cysteine

\begin{tabular}{ccccccccc}
\hline & \multicolumn{4}{c}{$\begin{array}{c}-\Delta G^{\circ} / \mathrm{kJ} \mathrm{mol}^{-1} \\
10^{2} \sigma_{M} / \mathrm{Cm}^{-2}\end{array}$} & \multicolumn{3}{c}{ Frumkin isotherm } & \multicolumn{4}{c}{$\begin{array}{c}-\Delta G^{\circ} / \mathrm{kJ} \mathrm{mol}^{-1} \\
\text { virial isotherm }\end{array}$} \\
\cline { 2 - 10 } & 1 & 3 & 5 & 7 & 1 & 3 & 5 & 7 \\
\hline-4 & 25.43 & 25.84 & 25.86 & 26.00 & 99.48 & 100.76 & 100.77 & 101.59 \\
-2 & 25.58 & 25.86 & 25.87 & 26.01 & 99.94 & 100.45 & 100.74 & 101.82 \\
0 & 25.74 & 26.00 & 26.04 & 26.40 & 100.39 & 101.26 & 101.54 & 102.45 \\
2 & 25.94 & 26.70 & 26.76 & 26.70 & 100.53 & 101.82 & 102.22 & 103.27 \\
4 & 25.98 & 26.78 & 26.81 & 26.84 & 100.73 & 101.99 & 102.68 & 103.93 \\
6 & 26.10 & 26.79 & 26.83 & 26.85 & 100.85 & 102.06 & 102.79 & 104.31 \\
8 & 26.14 & 26.82 & 26.90 & 26.91 & 100.90 & 102.07 & 102.85 & 105.30 \\
\hline
\end{tabular}

Table 3. Comparison of the Frumkin and virial isotherms constants for the chosen charges for $1-8 \mathrm{~mol} \mathrm{dm}^{-3}$ chlorates (VII) systems containing cysteine

\begin{tabular}{cccccccccc}
\hline & \multicolumn{4}{c}{$\begin{array}{c}A \\
c_{\text {chlorates(VII) }} / \mathrm{mol} \mathrm{dm}^{-3}\end{array}$} & \multicolumn{3}{c}{ Frumkin isotherm } & \multicolumn{4}{c}{$\begin{array}{c}B / \mathrm{nm}^{2} \text { molecule }^{-1} \\
\text { virial isotherm }\end{array}$} \\
\cline { 2 - 10 } & -4 & 0 & 4 & 8 & -4 & 0 & 4 & 8 \\
\hline 1 & 4.16 & 2.84 & 2.69 & 2.66 & 6.23 & 4.68 & 4.52 & 4.50 \\
2 & 3.12 & 2.74 & 2.63 & 2.60 & 4.87 & 4.63 & 4.50 & 4.45 \\
3 & 3.10 & 2.73 & 2.61 & 2.58 & 4.70 & 4.50 & 4.49 & 4.37 \\
4 & 2.85 & 2.69 & 2.60 & 2.57 & 4.32 & 4.24 & 4.21 & 4.00 \\
5 & 4.99 & 3.68 & 3.10 & 3.00 & 5.04 & 4.51 & 4.22 & 4.21 \\
6 & 8.09 & 6.14 & 4.80 & 4.24 & 5.27 & 4.57 & 4.26 & 4.23 \\
7 & 10.66 & 8.23 & 6.61 & 6.05 & 5.28 & 4.58 & 4.29 & 4.28 \\
8 & 15.06 & 13.85 & 12.91 & 11.68 & 5.30 & 4.60 & 4.41 & 4.33 \\
\hline
\end{tabular}

The obtained values of Frumkin and virial isotherm constants are presented in Table 2 and Table 3.

The changes of adsorption energy $\Delta G^{0}$ values obtained for the Frumkin isotherm as a function of the concentration of chlorate (VII) and electrode charge confirm analogous $\Delta G^{0}$ changes obtained for the virial isotherm. It should be emphasized that together with the increase of the supporting electrolyte concentration the values of $\Delta G^{0}$ are increasing. Increase of the $\Delta G^{0}$ value with the increase of positive electrode charge could be related to the extraction of water molecules from the electrode surface.

The values of the interaction parameter $A$ (calculated from the slopes of the lines on the linear test of the Frumkin isotherm) decrease with the increase of the electrode charge for all the supporting electrolyte concentrations examined. Such changes point at the decrease of a repulsive interaction between the adsorbed molecules $\mathrm{Hg}_{2}(\mathrm{SR})_{2}$ and $\mathrm{Hg}(\mathrm{SR})_{2}$. It is probably relat-

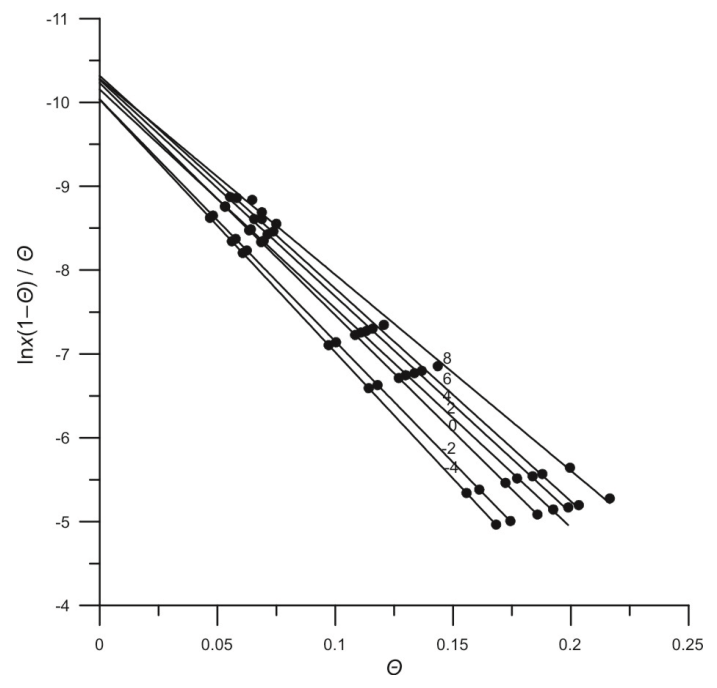

Figure 6. Linear test of the Frumkin isotherm for the system 8 $\mathrm{mol} \cdot \mathrm{dm}^{-3}$ chlorate (VII) + cysteine. Electrode charges $\sigma_{\mathrm{M}}$ (in $\mu \mathrm{C} \mathrm{cm}^{-2}$ ) indicated by each line. 
ed to the increase of $\mathrm{ClO}_{4}^{-}$anions adsorbing near protonated form of the adsorbates $\mathrm{Hg}_{2}(\mathrm{SR})_{2}$ and $\mathrm{Hg}(\mathrm{SR})_{2}$ and thus screening of the repulsive forces between the adsorbed molecules. This leads to the increase of adsorption of cysteine mercurous and mercuric thiolates which is indicated by the increase of $\Gamma^{\prime}$.

The increase of the supporting electrolyte concentration from 1 to $4 \mathrm{~mol} \mathrm{dm}^{-3}$ in all the range of studied charges causes the slight decrease of $A$ values. With the increase of chlorates (VII) concentration from 5 to 8 mol dm${ }^{-3}$ the values of $A$ increase considerably. A similar trend is observed for second virial coefficient $B$. It should be emphasized that together with the increase of the supporting electrolyte concentration the value of $\Delta G^{0}$ and repulsive interaction between the adsorbed molecules increase. It could suggest that the measure of adsorption magnitude is a resultant of these two parameters, what is manifested in dependences $\Gamma^{\prime}=f\left(c_{\text {adsorbate }}\right)$ for different concentrations of the supporting electrolyte (Figure 5).

\section{CONCLUSIONS}

Both the cysteine concentration and water activity have an essential influence on the double layer parameters on the interface mercury/ chlorates (VII). The adsorbate surface excess $\Gamma^{\prime}$ increases with the increase of cysteine concentration, the electrode charge as well as the supporting electrolyte concentration.

With increase of concentration of chlorate (VII) solution the standard Gibbs energy of adsorption and repulsive interaction between the adsorbed molecules $\mathrm{Hg}_{2}(\mathrm{SR})_{2}$ and $\mathrm{Hg}(\mathrm{SR})_{2}$ increase, whereas the values of integral capacity decrease. The changes of adsorption parameters in a function of the supporting electrolyte concentration point at competitive adsorption of cysteine mercurous $\mathrm{Hg}_{2}(\mathrm{SR})_{2}$, cysteine mercuric $\mathrm{Hg}(\mathrm{SR})_{2}$ thiolates and $\mathrm{ClO}_{4}^{-}$ions as well as electrostatic interaction between adsorbate and water molecules.

\section{REFERENCES}

1. E. Fink, Cosmetics, guide book to active and auxiliary substances (in Polish), MedPharm., Wrocław, 2007.

2. J. B. Matos, L. P. Pereira, S. M. L. Agostino, O. E. Barcia, G. G. O. Corderio, and E. D'Elia, J. Electroanal. Chem. 570 (2004) 91-94.

3. R. Brdička, Collect. Czech. Chem. Commun. 15 (1934) 167-180.
4. J. M. Kolthhoff, W. Stricks, and N. Tanaka, J. Am. Chem. Soc. 63 (1941) 520-526.

5. M. Březina, Collect. Czech. Chem. Commun. 24 (1959) 3509-3516.

6. P. Mader, J. Kita, and J. Volke, Collect. Czech. Chem. Commun. 33 (1968) 3625-3631.

7. I. R. Miller and J. Teva, J. Electroanal. Chem. 36 (1971) 1035 1040 .

8. M. Youssefi and R. L. Birke, Anal. Chem. 49 (1977) 1380-1385.

9. D. G. Davis and E. Blanco, J. Electroanal. Chem. 12 (1966) 254-260.

10. P. Anzenbacher and V. Kalous, Collect. Czech. Chem. Commun. 38 (1973) 2418-2424

11. A. M. Bond., S. B. Thomson, D. J. Tucker, and M. H. Briggs, Anal. Chem. Acta 156 (1984) 33-42.

12. M. Stankovich and A. J. Bard, J. Electroanal. Chem. 75 (1977) 487-505.

13. M. Heyrovský, P. Mader, V. Veselá, and M. Fedurco, J. Electroanal. Chem. 369 (1994) 53-70.

14. M. Heyrovský, P. Mader, S. Vavřička, V. Veselá, and M. Fedurco, J. Electroanal. Chem. 430 (1997) 103-117.

15. B. Monterroso-Marco and B. López-Ruiz, Talanta 61 (2003) 733-741.

16. M. Lovrić, I. Pižeta, and Š. Komorsky- Lovrić, Electroanalysis 4 (1992) 327-330.

17. V. Mirčeski and M. Lovrić, Electroanalysis 10 (1998) 976-983.

18. R. Piech and W. W. Kubiak, Electrochim. Acta 53 (2007) 584-589.

19. J. W. Schultze and F. D. Koppitz, Electrochim. Acta 21 (1976) 327-329.

20. A. Szulborska and A. Baranski, J. Electroanal. Chem. 337 (1994) 269-281.

21. A. Nosal-Wiercińska and G. Dalmata, Electroanalysis 22 (2010) 2081-2087.

22. G. Dalmata and A. Nosal-Wiercińska, Croat. Chem. Acta 81 (2008) 529-537.

23. Z. Galus, Electroanalytical Methods of Determination of Physicochemical Constants (in Polish), PWN, Warsaw, 1979, p. 70.

24. D. C. Grahame, R. P. Larsen, and M. A. Poth, J. Am. Chem. Soc. 71 (1949) 2978-2983.

25. D. C. Grahame, E. M. Coffin, J. J. Commings, and M. A. Poth, J. Am. Chem. Soc. 74 (1952) 1207-1211.

26. D. J. Schiffrin, J. Electroanal. Chem. 23 (1969) 168-171.

27. A. De Battisti, S. Trasatti, J. Electroanal. Chem. 54 (1974) 1-17.

28. D. M. Mohilner and H. Nakadomari, J. Phys. Chem. 74 (1973) 1594-1598.

29. D. M. Mohilner, L. W. Browman, S. J. Freeland, and H. Nakadomari, J. Electrochem. Soc. 120 (1973) 1658-1662.

30. R. Parsons, Trans. Faraday Soc. 51 (1955) 1518-1529.

31. Š. Komorsky-Lovrić, M. Lovrić, and M. Branica, J. Electrochem. Soc. 140 (1993) 1850-1853.

32. R. Parsons and R. M. Reeves, J. Electroanal. Chem. 123 (1981) 141-149.

33. R. Parsons, J. Electroanal. Chem. 118 (1981) 3-18.

34. R. Parsons and R. Payne, J. Electroanal. Chem. 357 (1993) 327-338. 